\title{
EXPERIMENTAL ANAL YSIS OF FAILURES IN FILLED HOLE COMPRESSION TESTS OF CARBON/EPOXY LAMINATE
}

\author{
B. Castanié ${ }^{1,2}$, S. Crézé ${ }^{1}$ J.J. Barrau ${ }^{1}$, F. Lachaud ${ }^{1}$, L. Risse ${ }^{3}$ \\ ${ }^{1}$ Université de Toulouse, INSA,UPS, Mines d'Albi, ISAE; ICA (Institut Clément Ader), \\ ${ }^{2}$ INSA, 135 Avenue de Rangueil, 31077 Toulouse, France. \\ ${ }^{3}$ Airbus France, 316 Route de Bayonne, 31000 Toulouse
}

\begin{abstract}
.
In this study, failure modes occurring during Filled Hole Compression (FHC) tests were analysed using post-mortem analysis for failure pattern identification and high-speed cameras for failure scenario (damage initiation and progress). Two different failure scenario were experienced depending upon the stacking sequence :

* Net compression failure for high $0^{\circ}$ oriented lay-ups. The crack initiation is observed near the bolt but the location differs with bolt tightening or not, enabling future validation of finite element models.

* Off-set compression failure for low oriented lay-ups. This failure mode was attributed to bearing by-pass loads in the literature. Nevertheless, this study demonstrates that a different scenario can occur linked to a specimen effect: first a delamination appears at the free edges of the specimens. Then, as the delamination area grows, a local buckling occurs creating a net failure at the tip of the wave.

The results obtained in this study are the basis for developing more robust sizing methods for bolted joints based on physical understanding of failure mechanism and associated sensitivity parameters.
\end{abstract}

*Corresponding author: bruno.castanie@insa-toulouse.fr, Tel: 33 (0)5.62.17.81.16. Fax: 33.(0)5.61.55.81.78. 


\section{Keywords.}

Net Compression Failure, off-set Failure, Filled Hole Compression.

\section{1-Introduction.}

Filled hole compression tests are usually conducted in the purpose for determining allowables $\left(\sigma_{0}\right.$ and $\left.\mathrm{d}_{0}\right)$ which are necessary for the application of point-stress method [1]. Classical failure modes are described in the US Military Handbook [2] and several studies (for example [3]-[4]). Most studies focus on the modelling and experimental identification of damage in fastened joints or pinned hole ([5], [6]), and on the influence of design: clearance, tightening effect or washer effects ([8], [7], [9], [10], [11]). A particular attention was paid to the experimental identification and modelling of bearing failures ([12],[13]) and recently to manufacturing effects $([14],[15])$. It is noticeable that most studies deal with single or double lap joint. Less attention was dedicated to Filled Hole Tension (FHT) [16] or Compression (FHC) tests [17]. In the last case a particular failure mode may occur and is reported by [2] and was observed in [17]: the laminate off-set compression failure (see also Figure 1). This failure was attributed to bearing loads. In this experimental study, this mode was also observed by classical post-mortem analysis but further investigation were conducted using high speed cameras to capture the failure scenario.

\section{2- Specimens and tests description.}

A plate is manufactured by manually laying up unidirectional plies of pre-impregnated carbon laminate (intermediary modulus and epoxy resin). After curing, the specimens are cut out following different orientations (see Figure $\mathrm{N}^{\circ}$ 2). In the $\mathrm{X}$-axis, the stacking includes 10 plies at $0^{\circ}, 4$ plies at $45^{\circ}, 4$ plies at $135^{\circ}$ and 2 plies at $90^{\circ}$. The stacking sequence is $\left[0_{2}, 45,90,-\right.$ $45,0,45,0,-45,0]_{\mathrm{s}}$. This lay-up is referred to [10/4/4/2] in the following. In the Y-Axis, the 
stacking sequence is thus $[2 / 4 / 4 / 10]$. The specimen is designed according to the European standard of holed composite specimen for compressive load tests (DIN EN ISO 14126). The thickness of the specimen is about $5 \mathrm{~mm}$ and the dimensions of the specimen are $32 \mathrm{~mm}$ wide and $142 \mathrm{~mm}$ long. Fibre glass reinforcement of $55 \mathrm{~mm}$ long are bonded on the both sides of the specimens (see Figure $\mathrm{N}^{\circ}$ 3). A $6.35 \mathrm{~mm}$ hole is drilled at the centre of the specimens. Several specimens are not drilled to get a reference.

Three effects are studied:

-Torque/lateral constraint: some specimens were tested with bolt but no nut, some with finger tight torque.

-Bolt material: Titanium or Steel.

-Lay-up/off axis: $0^{\circ}([10 / 4 / 4 / 2]), 90^{\circ}([2 / 4 / 4 / 10])$ and off-axis: $22.5^{\circ}, 45^{\circ}, 67.5^{\circ}$

(Figure $\mathrm{N}^{\circ}$ 2). All the off-axis specimens hold a titanium bolt with finger tight torque.

For each configuration, three tests are carried out to get an evaluation of the scattering. A total of 39 specimens are tested. The effect of clearance is not studied specifically but after measurements, it was observed that it remains under $50 \mu \mathrm{m}$. To verify the linearity of the loading, all the specimens are equipped with a pair of strain gauges on both the front and the back sides of the specimens. These gauges were bonded in the net section.

The test set-up is showed Figure $N^{\circ} 4(\mathrm{a})$. A $160 \mathrm{kN}$ compression test machine is used with hydraulic grips. The load cell of the machine provides the compression force and the loading rate is $1 \mathrm{~mm} / \mathrm{mn}$. A high speed camera (set at 10000 pictures/second) is necessary to capture the damage scenario (Figure $\mathrm{N}^{\circ} 4(\mathrm{~b})$ ). The use of cold light spotlights is required because the temperature of the specimen increases quickly with classical spotlight. Even with this apparatus, a ventilator and a thermocouple are installed to monitor properly the temperature of the specimen (see principle Figure $\mathrm{N}^{\circ}$ ). As the frequency of the high speed camera is very short (a sliding window of several seconds), digital camcorder are also used and installed on both side of the specimen to capture slow events. Moreover, for several tests, two mirrors were installed on the side of the specimen and oriented at $45^{\circ}$ (see Figure $\mathrm{N}^{\circ}$ 5). It was thus possible to analyse the events which occurs trough the thickness of the edges of the specimens. 


\section{3- Static results and Post-mortem analysis.}

The strain gauges measurement are not provided here since the response is quasi linear until failure. Only parasitic bending moments were identified due to a small curvature of the specimens. The failure loads with scatter bars are given Figure $\mathrm{N}^{\circ} 6$. The values are the average of the three tests carried out for each configuration and are normalized by respect to the value of the [10/4/4/2] stacking reference specimen fixed to 100 .

The following remarks can be highlighted:

-Filled hole effect: The failure load decreases between the reference and the drilled specimens for the [10/4/4/2] stacking but remain almost the same for [2/4/4/10] stacking. (42 for the reference, between 39 to 42 with bolts).

-Off-axis effect: In the case of filled hole with tightened bolt, the failure load increases continuously as the off-axis difference decreases.

-Bolt material effect: for [2/4/4/10] stacking, it is not possible to identify a clear trend on the influence of bolt material because the differences are about $5 \%$ and hidden by the scatter. However, this result is consistent with the flexibility of this stacking. For stacking [10/4/4/2], the sensitivity to the bolt material seems to be more important especially for the tightened specimens.

-Lateral constraint effect: for [2/4/4/10] stacking, it is not possible to identify a clear trend because the differences are about $5 \%$ and hidden by the scatter. For $[10 /$ 4/4/2] stacking, the normalized load for a tightened titanium bolt is 86 and decrease to 76 for a non tightened specimen, i.e $-12 \%$. This result is in opposition with the literature. Usually, tightening a bolt has a positive effect by containment of the bearing or by the effect of transverse compressive stresses on the delamination onset. For the steel bolt, it is not possible to conclude because the scatter is too high.

To understand this behavior, a classical post-mortem analysis was first performed.

Sample of failures patterns for [10/4/4/2] specimens are shown Figure $\mathrm{N}^{\circ} 7$ (tightened bolt) 
and Figure $\mathrm{N}^{\circ} 8$ (no lateral constraint). Several failure modes are superimposed with net section compression failure and cleavage. On the edges of the specimens, delamination are also observed. Generally speaking, the pattern is different between the kind of specimen and one can assumes that the failure scenario is different. Sample of failures patterns for [2/4/4/10] specimens are shown Figure $\mathrm{N}^{\circ}$ 9. Unlike the previous tests, it is not necessary to make a difference between tightened or not specimens. For all the specimens, fracture lines are clearly visible in the net section (Specimen A) or in off-set sections (specimens B and C). Nevertheless, for tightened specimens the fracture line is always tangent to the bolt. On the edges of the specimens, delaminations are also visible (Specimen C). The different fracture line patterns are summarized in Figure $\mathrm{N}^{\circ} 10$.

The failure patterns for the off-axis specimen are showed Figure $\mathrm{N}^{\circ} 11$. The fracture lines follow the main direction of the axis and are not located in the net section. For this original failure pattern, one can speak of "generalized off-set failure".

This classical post-mortem analysis shows that for all the specimens cracks appears in the net or in off-set sections and seems to be the main failure mode. In order to better understand the failure scenarios, a more advanced experimental analysis was carried out by using high speed camera.

\section{4- High speed camera analysis: identification of the failure scenario.}

When tested, all the specimen failed in an explosive way and no difference could be visually observed. However, using high speed camera, different failure sequences and speeds were recorded: from $1 / 100^{\text {th }}$ to $1 / 10000^{\text {th }}$ second. The three pictures of Figure $\mathrm{N}^{\circ} 12$ show the failure sequence in a [10/4/4/2] specimen with a tightened bolt. The crack initiates at the periphery of the bolt for all the specimens with a little off-set from the net section. It then propagates relatively slowly (within several $1 / 1000^{\text {th }}$ second) to the edge of the specimen.

The three pictures of Figure $N^{\circ} 13$ show the crack propagation of a [10/4/4/2] specimen with no lateral constraint. The crack initiates in the net section near the bolt and propagates in an explosive way. Therefore, the three pictures were taken every $1 / 10000^{\text {th }}$ second. For both cases, the final failure mode is a static failure of the upper ply oriented at $0^{\circ}$. However, the presence of the nut has however an effect on the location of the initiation of the crack. As the failure seems to be a pure static failure, the bearing stresses and the delaminations may not have any influence. So the tightening modifies the local triaxial stress concentration and load transfer between the hole and the bolt and can explain the difference observed in the failure 
loads between the specimens. However, this assumption is still to be demonstrated by a numerical analysis.

In the sequence of pictures given Figure $\mathrm{N}^{\circ} 14$, a phenomenon of material ejection is showed. It is localized in the edge of a [2/4/4/10] stacking specimen. This phenomenon was observed only for this stacking and for all the configuration of bolts. The four pictures were taken every $1 / 10000^{\text {th }}$ second, so it is nearly explosive. Moreover, the location of the ejection was never in the net section. It occurs prior to any apparent damage and nothing was detected on the load/displacement curves. In order to identify the mechanisms, some mirrors were installed as described in paragraph 2 and Figure $\mathrm{N}^{\circ} 5$.

In the sequence of pictures given Figure $N^{\circ} 15$, the failure scenario for [2/4/4/10] specimen is showed. Thanks to the mirror, the apparition of a delamination in the edge can be observed (Step 1). Clearly, interlaminar normal and shear stresses occurring in the region near the free edge due to high stress gradients can cause this delamination [18]. Moreover, this observation is consistent with the previous phenomenon of material ejection which seems to correspond to the onset of delamination (Figure $\mathrm{N}^{\circ} 14$ ). Afterwards, the delamination propagates relatively slowly (Step 2). The sequence takes about $1 / 100^{\text {th }}$ second. When the delamination area is large enough, a local buckling of the upper plies occurs (Step 3), and a net failure at the tip of the wave happens immediately (Step 3). It is this fracture line which can be observed in the postmortem pattern (Figure $\mathrm{N}^{\circ} 9$ and Figure $\mathrm{N}^{\circ} 10$ ). This scenario explains the fact that due to a tightened bold, the buckling wave is always located at the same place. Thus, the stress concentration occurs at the periphery of the bolt and the fracture line initiates only at this place.

For specimens with no lateral constraint, the wave depends on the delamination which initiates randomly along the edge of the specimen. Thus the tip of the wave can be located anywhere, even in the net section as described Figure $\mathrm{N}^{\circ} 10$. So for this configuration, the offset failures cannot be attributed to bearing by-pass failures, as in reference [2]. The off-set failures are due to a specimen effect. It is noticeable that the same scenario was identified for off-axis specimens. A delamination initiates in the edges of the specimens and a local buckling occurs afterwards generating off-axis and off-set fracture lines.

\section{5-Conclusions.}

An advanced experimental study was conducted on Filled Hole Compression test of carbon/epoxy specimens. For the configurations analysed, net compression failures were 
observed for [10/4/4/2] stacking. It was due to stress concentration that located at the periphery of the bolt or the drilled hole. For [2/4/4/10] and off-axis stackings, off-set failures were identified. These failures were not due to bearing stresses but to an edge delamination, followed by a local buckling. The results obtained in this study are the basis for developing more robust sizing methods for bolted joints based on physical understanding of failure mechanism and associated sensitivity parameters. More specifically, the results obtained (specimen edge effects) invalidate the classical point-stress method for some cases.

\section{6-References.}

[1] Whitney J.M., Nuismer J.: Stress criteria for laminated composites containing stress concentration. Journal of composite materials 1974: 8; 254-264.

[2] US Mil-Hbk 17A, Chapter 7: Structural Element Characterization..

[3] Hung C-L., Chang F-K.: Strength Envelope of Bolted Composite Joints under Bypass Loads. Journal of Composite Materials 1996; 30; 1402

[4] Valenza A., Fiore V., Borsellino C.,Calabrese L., Di Bella G.: Failure Map of Composite Laminate Mechanical Joint. Journal of Composite Materials 2007; 41; 951.

[5] Persson E., Madenci E., Eriksson I.: Delamination initiation of laminates with pin-loaded holes. Theoretical and Applied Fracture Mechanics 1998; 30:87-101.

[6] T. Ireman, T. Ranvik et I. Erikksson, "On damage development in mechanically fastened composite laminates", Composite Structures, vol. 49, 2000.

[7] M.A. McCarthy, V.P. Lawlor, W.F. Stanley er C.T. McCarthy, "Bolt-hole clearance effects and strength criteria in single-bolt, single-lap, composite bolted joints", Composite Science and Technology 2002 , vol. 62, pp. 1415-1431,

[8] Naik R.A.., Crews J.H.: Stress analysis method for clearance fit-bolt under bearings load. AIAA Journal 1985; 24: 1348-1353.

[9] .L. Tong: Bearing failure of composite bolted joints with non-uniform bolt-to-washer clearance, Composites Part A: Applied science and manufacturing 2000, vol. 31, pp. 609-615, 2000.

[10] H.-J. Park: Effects of stacking sequence and clamping force on the bearing strengths of mechanically fastened joints in composite laminates", Composite Structures 2001; 53: 213-221.

[11] H.-J. Park: Bearing failure analysis of mechanically fastened joints in composite laminates". Composite Structures 2001; 53: 199-211. 
[12] Wang H.-S., Hung C.-L. Chang F.-K.: Bearing failure of bolted composite joints. Part I: Experimental characterization", Journal of composite materials 1996; 30(12):

[13] Hung C.-L., Chang F.-K.: Bearing failure of bolted composite joints. Part II: Model and verification, Journal of composite materials 1996; 30(12):1359-1400.

[14] G. Gohorianu, R. Piquet, F. Lachaud, J-J Barrau, "Composite bolted joints behaviour: Effects of hole machining defects", Second international conference on Joining Plastics 2006, National Physical Laboratory (NPL), London, G-B., april 2006.

[15] Gohorianu G. Interaction between drilling defects and bearing behaviour of carbon/epoxy bolted joints, PHD thesis, ISAE, 2008, http://thesesups.ups-tlse.fr/248/1/Gohorianu_Gina.pdf.

[16] .Y. Yan, W.-D. Wen, F.-K Chang et P. Shyprykevich, "Experimental study on clamping effects on the tensile strength of composite plates with a bolt-filed hole", Composite Part A, Applied science and manufacturing, vol. 30, $\mathrm{n}^{\circ}$ 10, pp. 1215-1229, 1999.

[17] Sawicki A.J., Minguet P.J.: The influence of fastener clearance upon the failure of compression loadec composite bolted joints. ASTM STP 1383, pp 293-308.

[18] Wang J. , Dickson J. N.: Interlaminar Stresses in Symmetric Composite Laminates. Journal of Composite Materials 1978; 12; 390-402. 


\section{FIGURES}

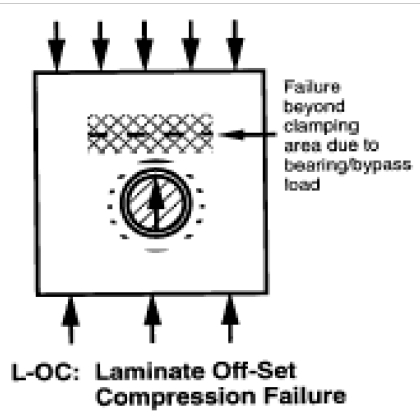

Figure $N^{\circ}$ 1: Laminate off-set failure (reproduced from [1]).

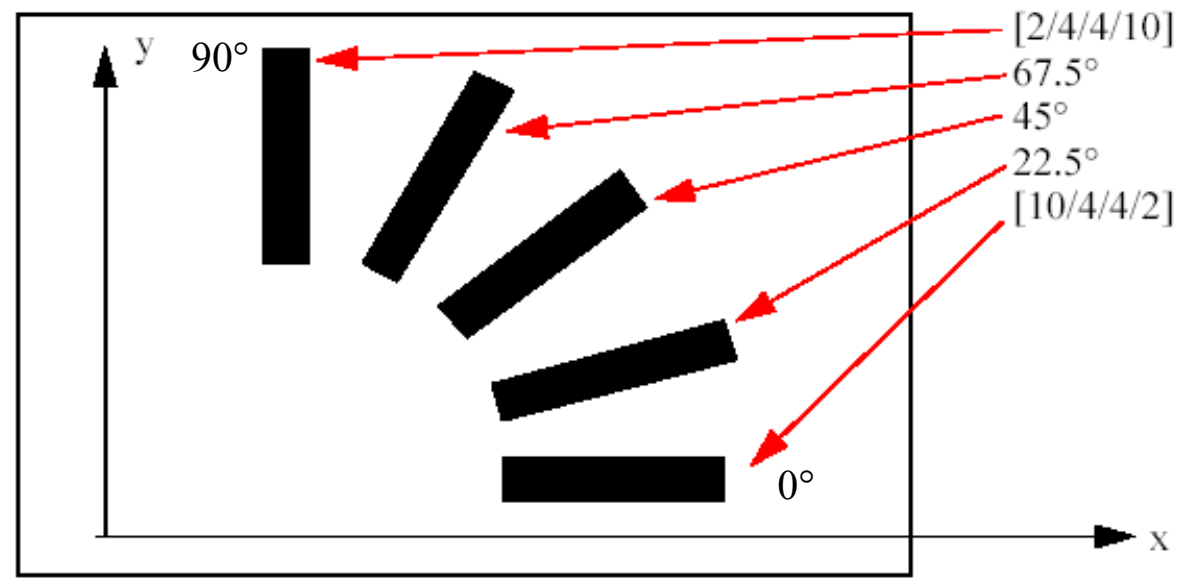

Figure $N^{\circ} 2$ : Cutting drawing of specimens.

\section{IN: 124334}

\section{TYPE 1.5}

Figure $N^{\circ} 3$ : Specimen sample. 


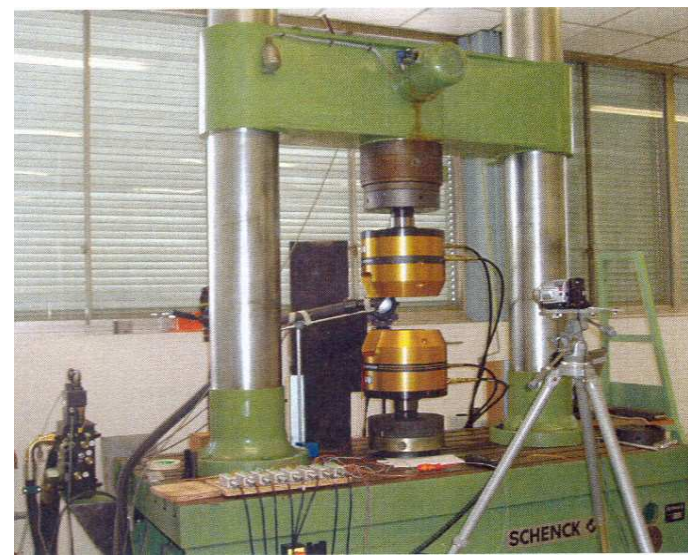

(a) $160 \mathrm{kN}$ compression test machine

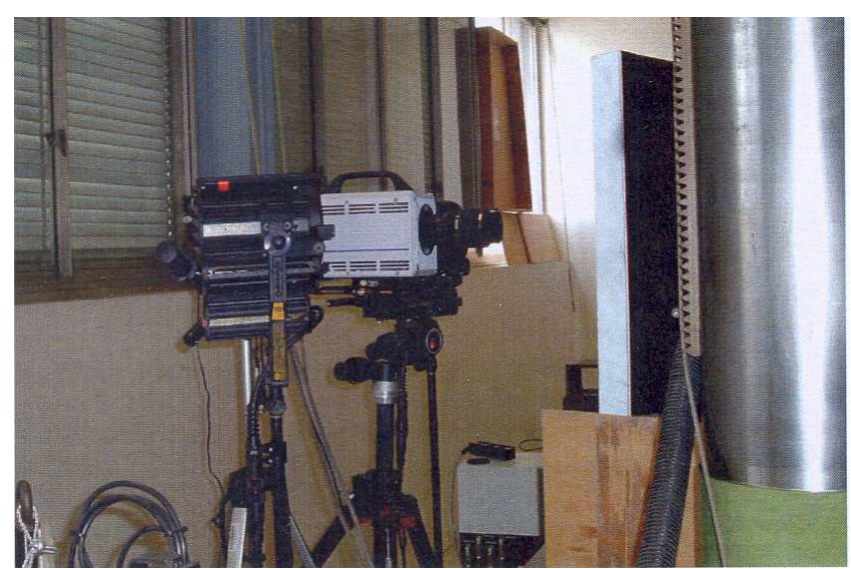

(b) High-speed camera with white spotlights

Figure $N^{\circ} 4$ : General views of tests apparatus.
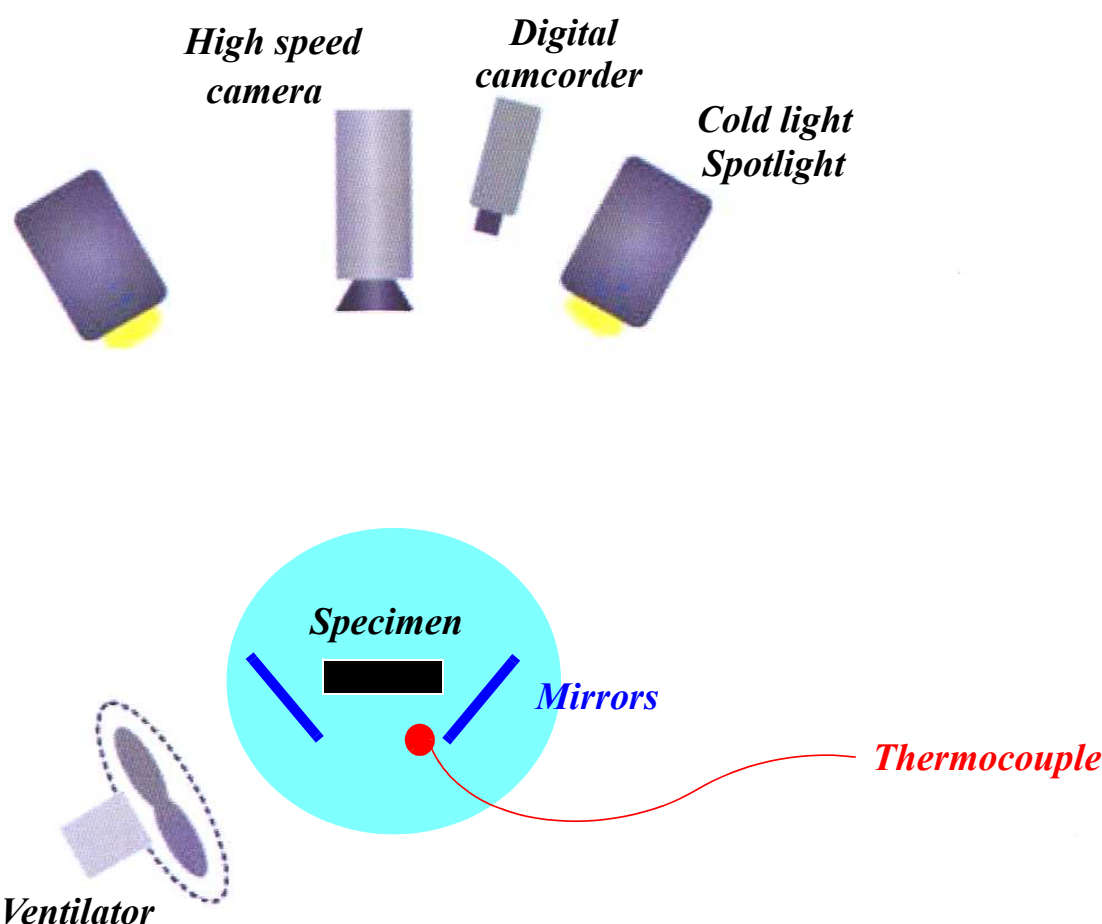

\section{Ventilator}

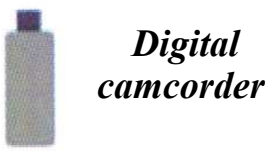

Figure $N^{\circ} 5$ : Test set-up principle. 


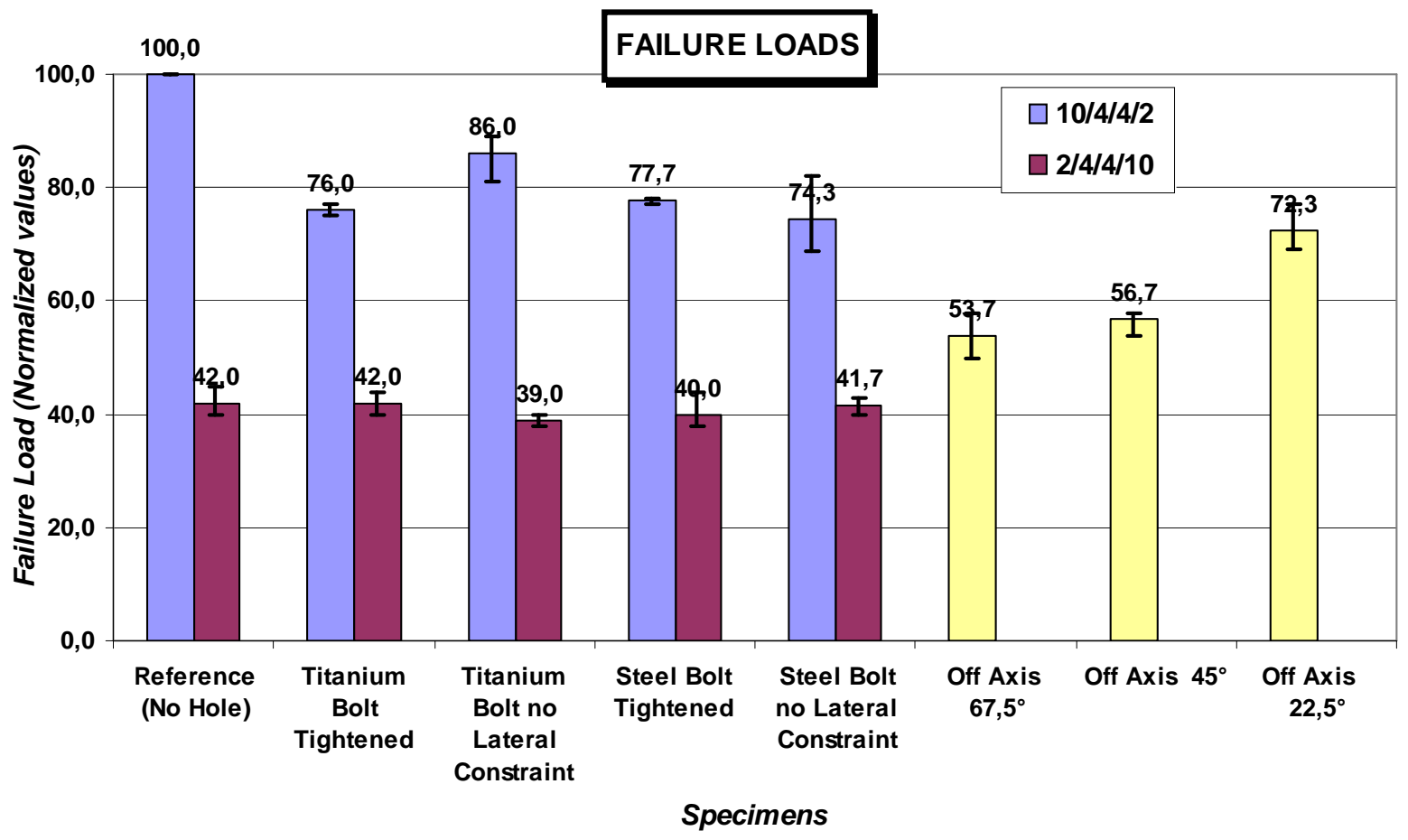

Figure $N^{\circ} 6$ : Failure loads for FHC Tests. 

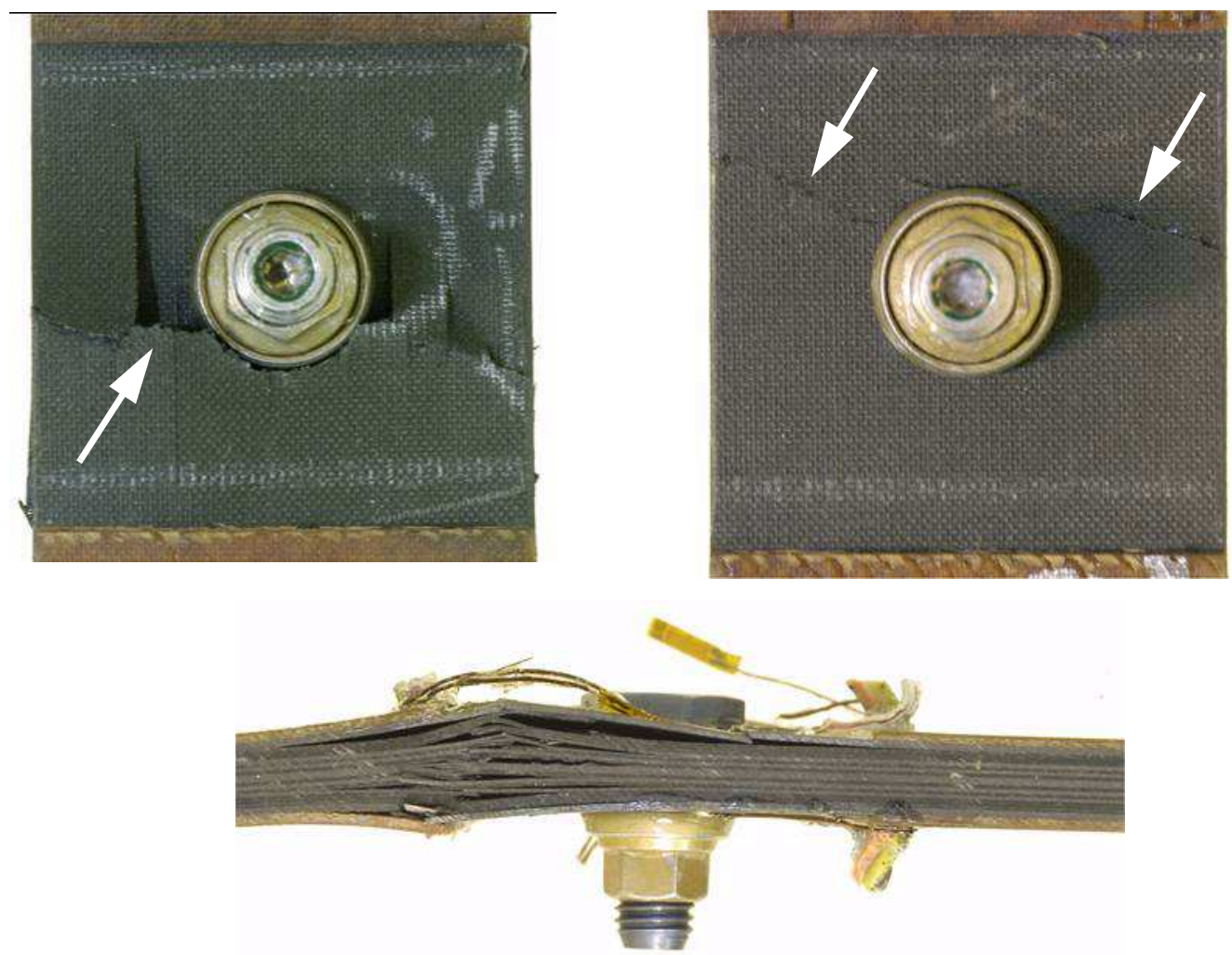

Figure $N^{\circ} 7$ : Post-mortem failure patterns of [10/4/4/2] specimens with tightened bolts.
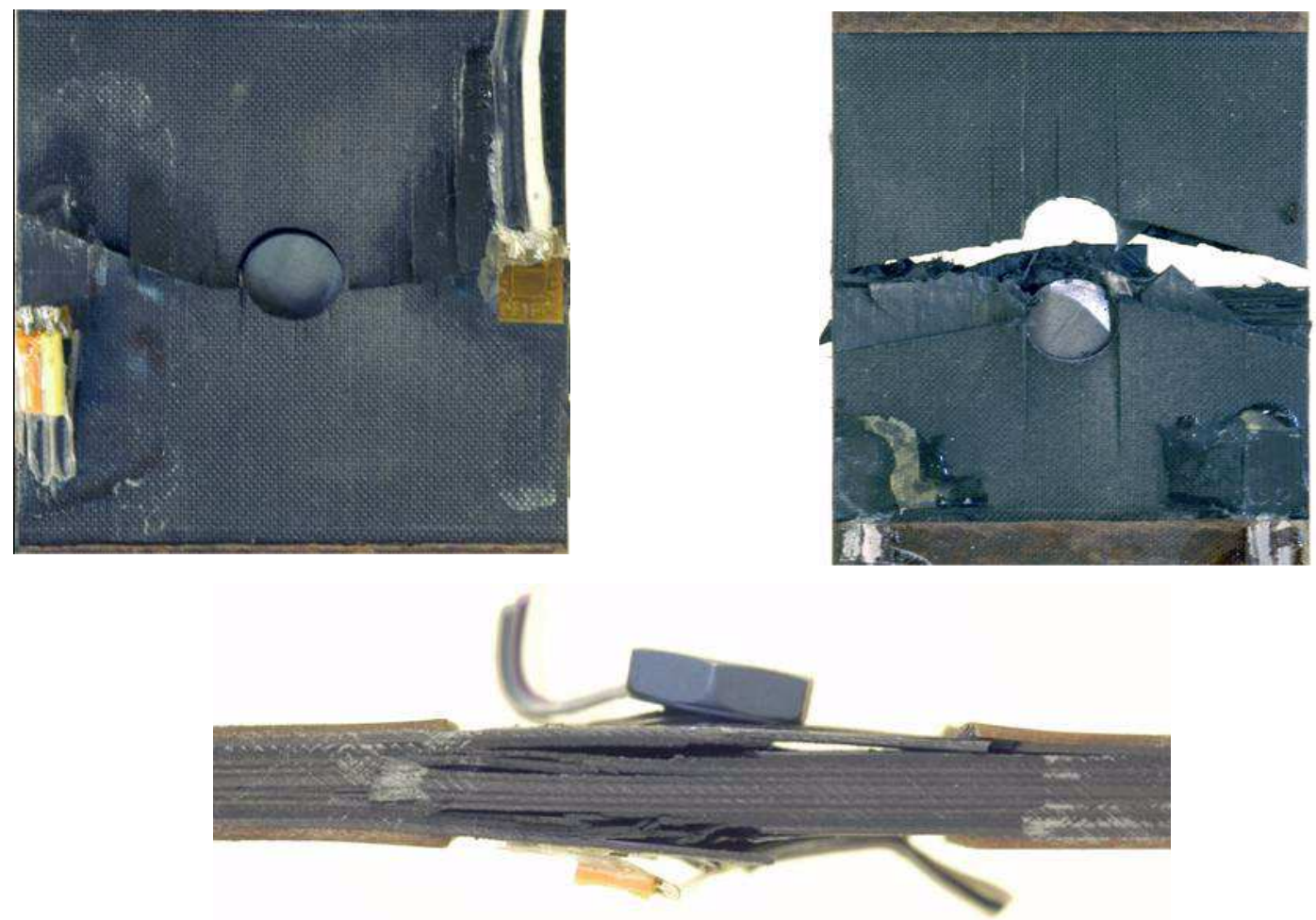

Figure $N^{\circ} 8$ : Post-mortem failure patterns of [10/4/4/2] specimens with no lateral constraint. 

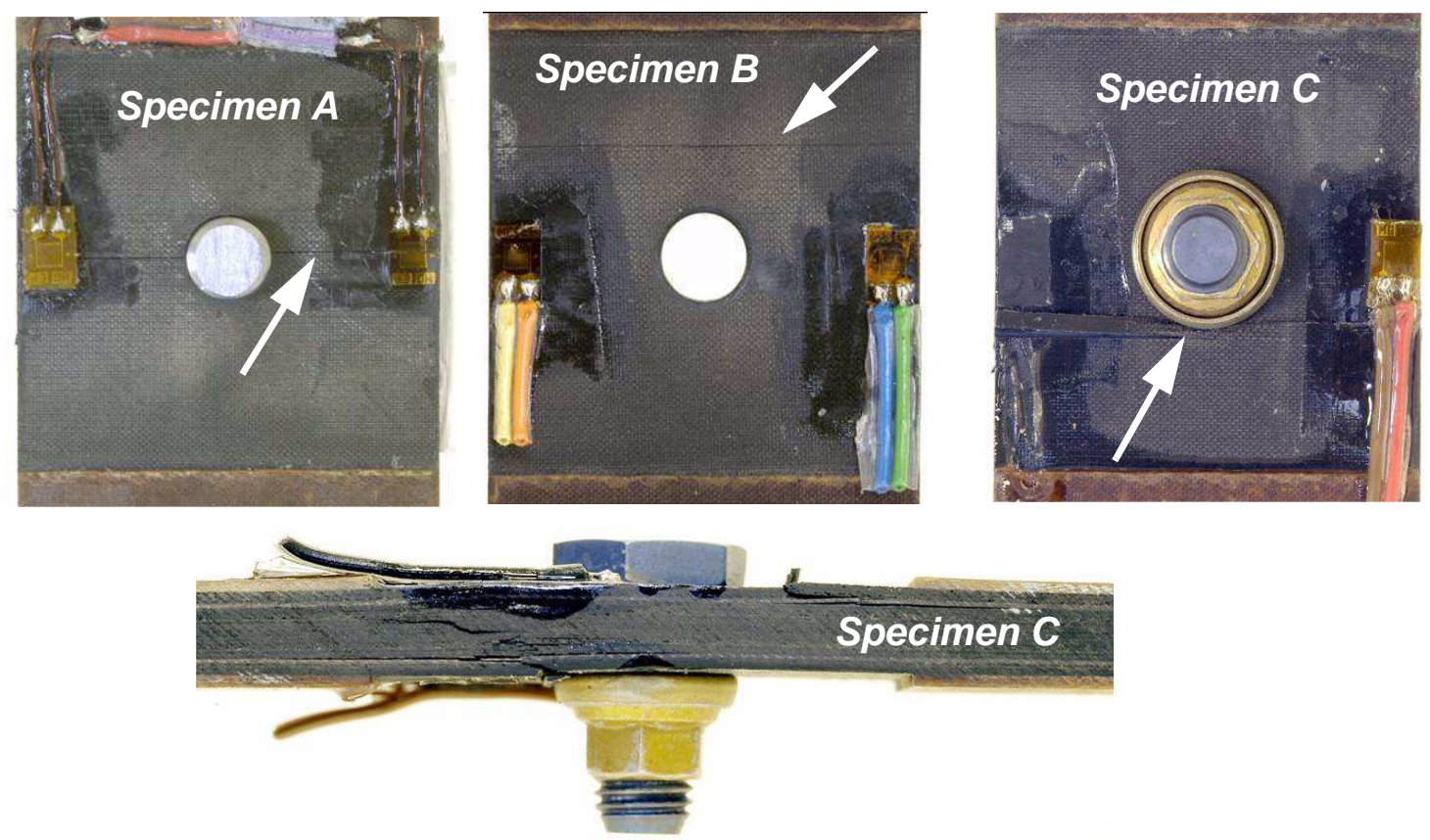

Figure $N^{\circ}$ 9: Post-mortem failure patterns of [2/4/4/10] specimens $A, B$ and $C$.

\section{[10/4/4/2]}

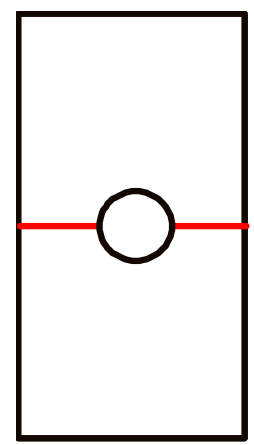

NO LATERAL CONSTRAINT

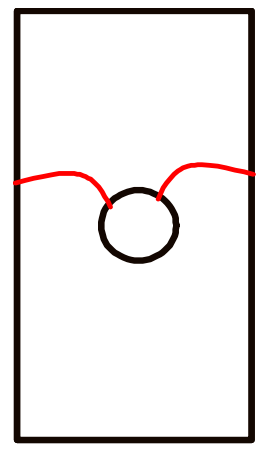

TIGHTENED
[2/4/4/10]

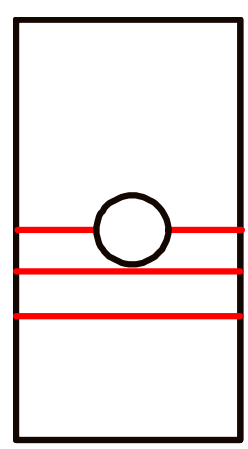

NO LATERAL CONSTRAINT

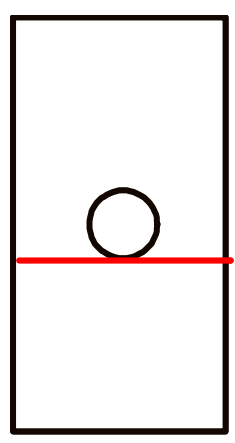

TIGHTENED

Figure $N^{\circ} 10$ : Fracture line locations. 

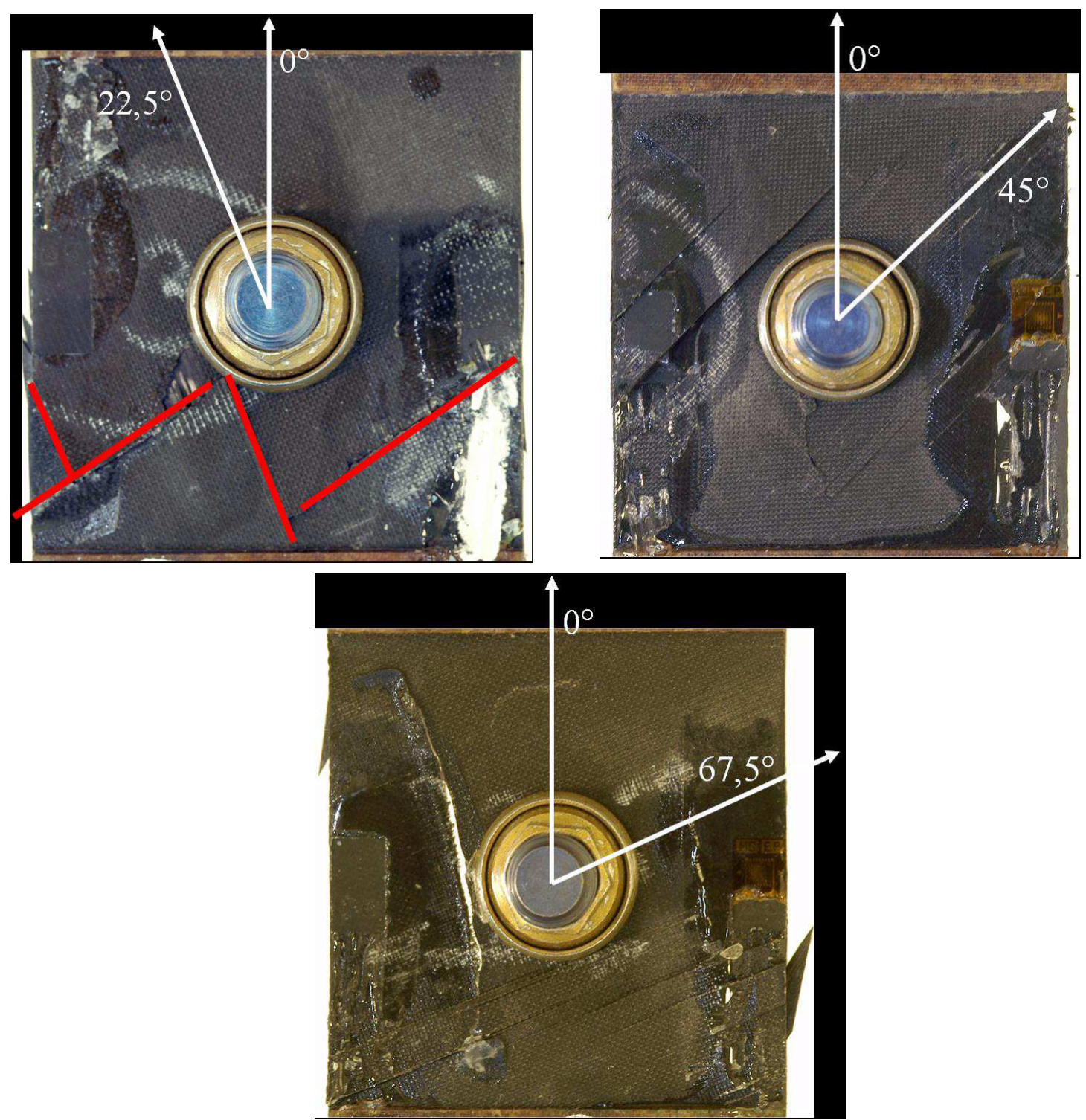

Figure $N^{\circ} 11$ : Failure pattern of off-axis specimens . 

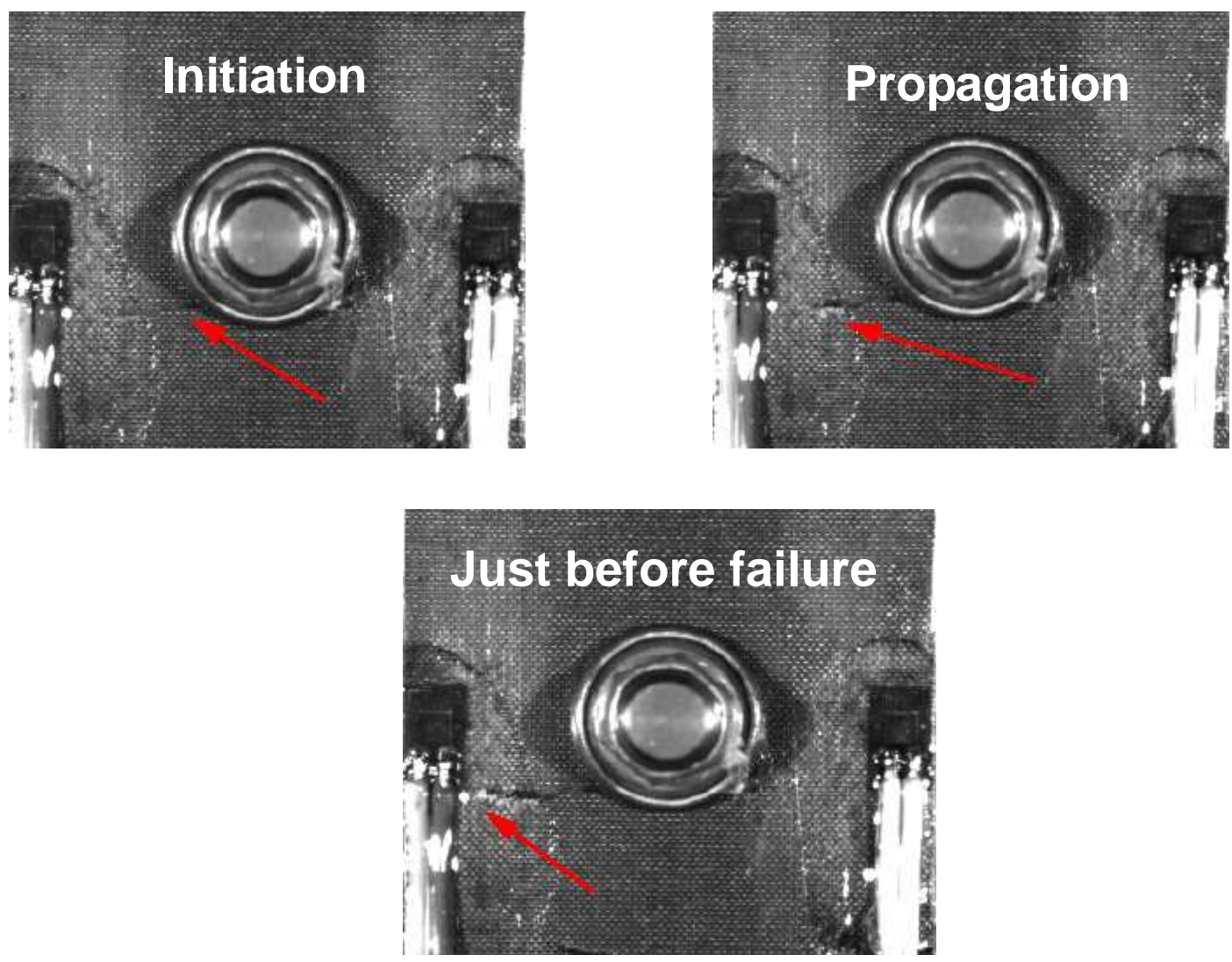

Figure $N^{\circ} 12$ : Failure of a [10/4/4/2] specimen with a tightened bolt.
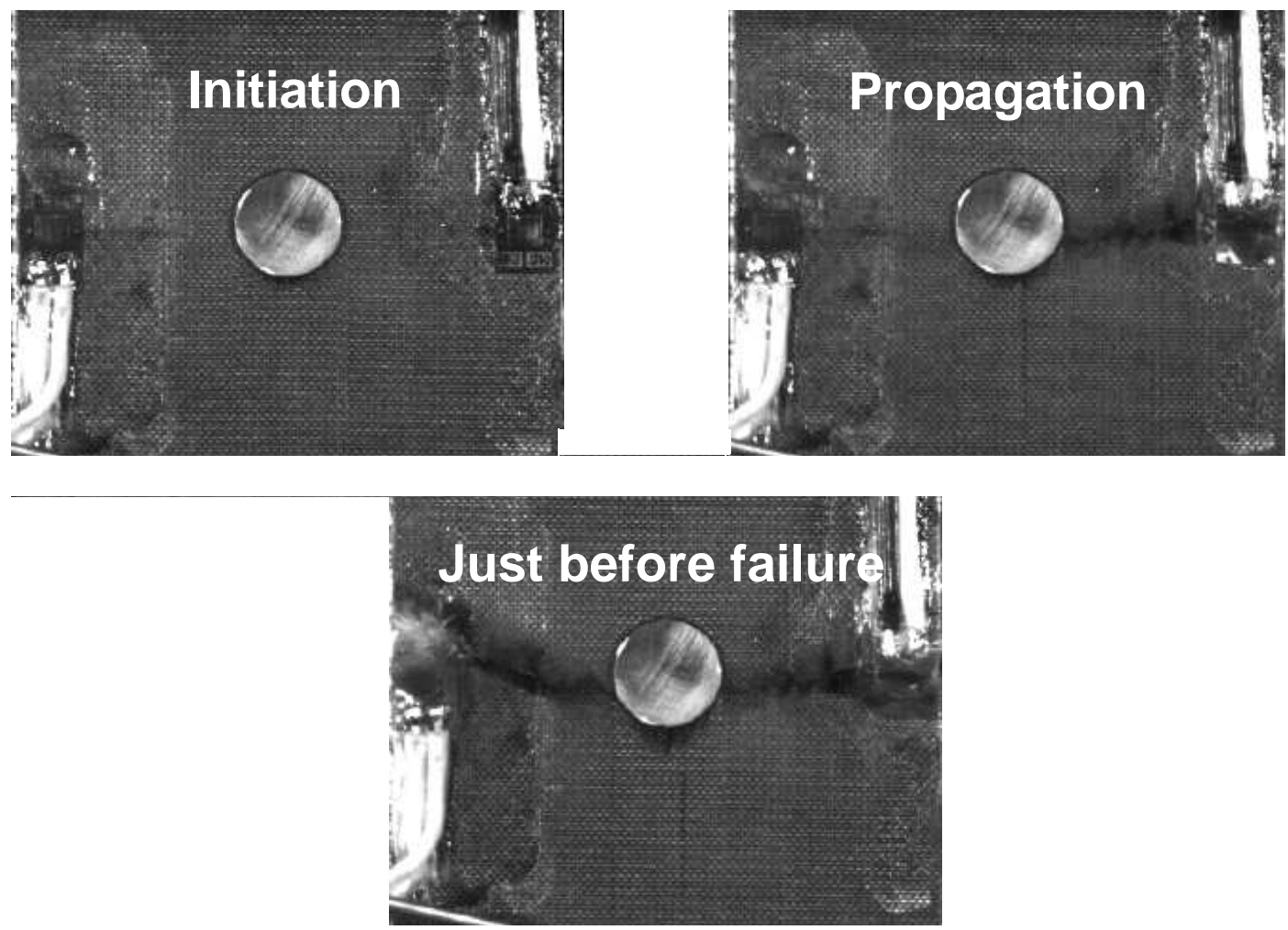

Figure $N^{\circ} 13$ : Failure of a [10/4/4/2] specimen with no lateral constraint. 

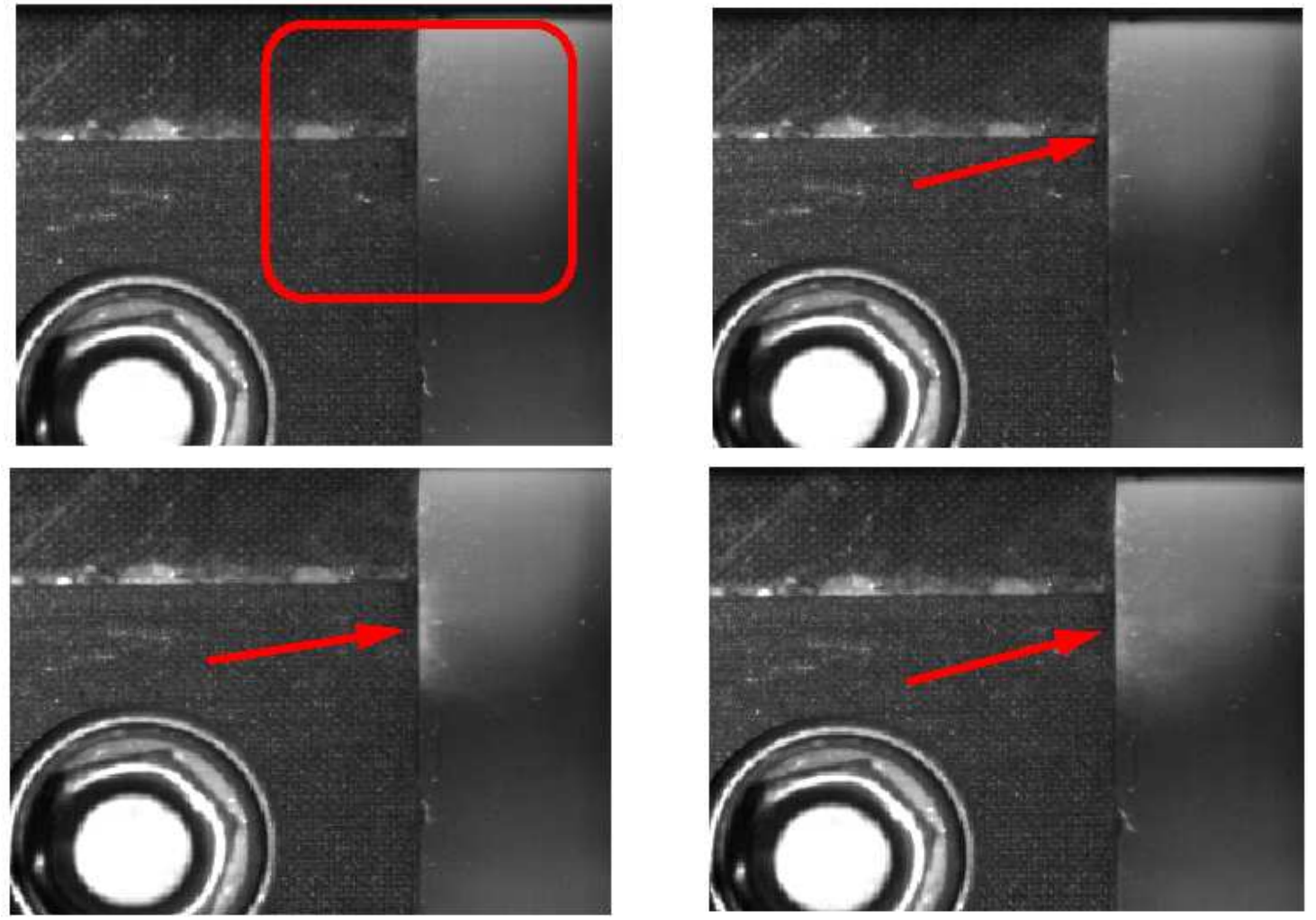

Figure $N^{\circ} 14$ : Material ejection phenomenon of [2/4/4/10] stacking specimen. 


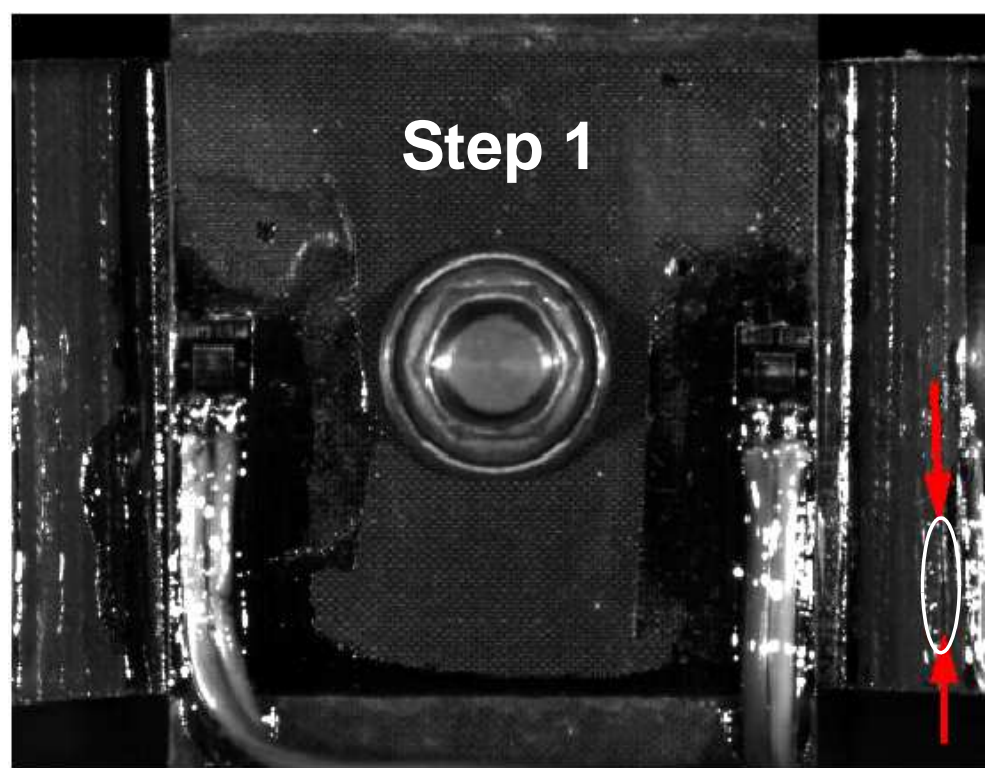

Delamination

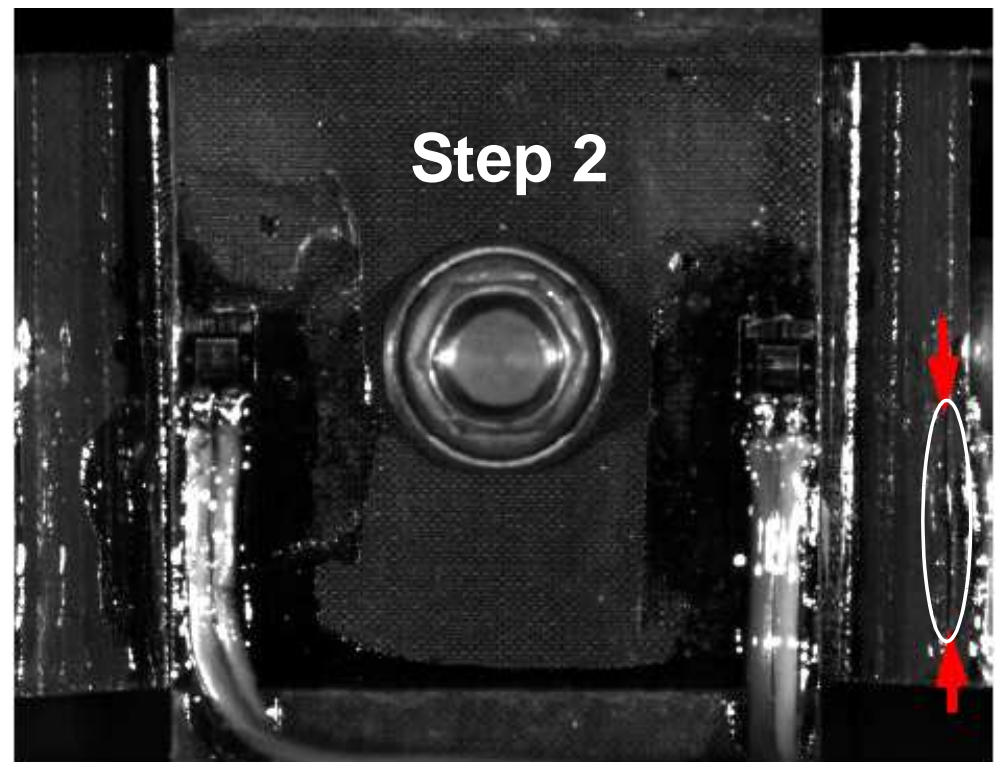

Delamination propagation

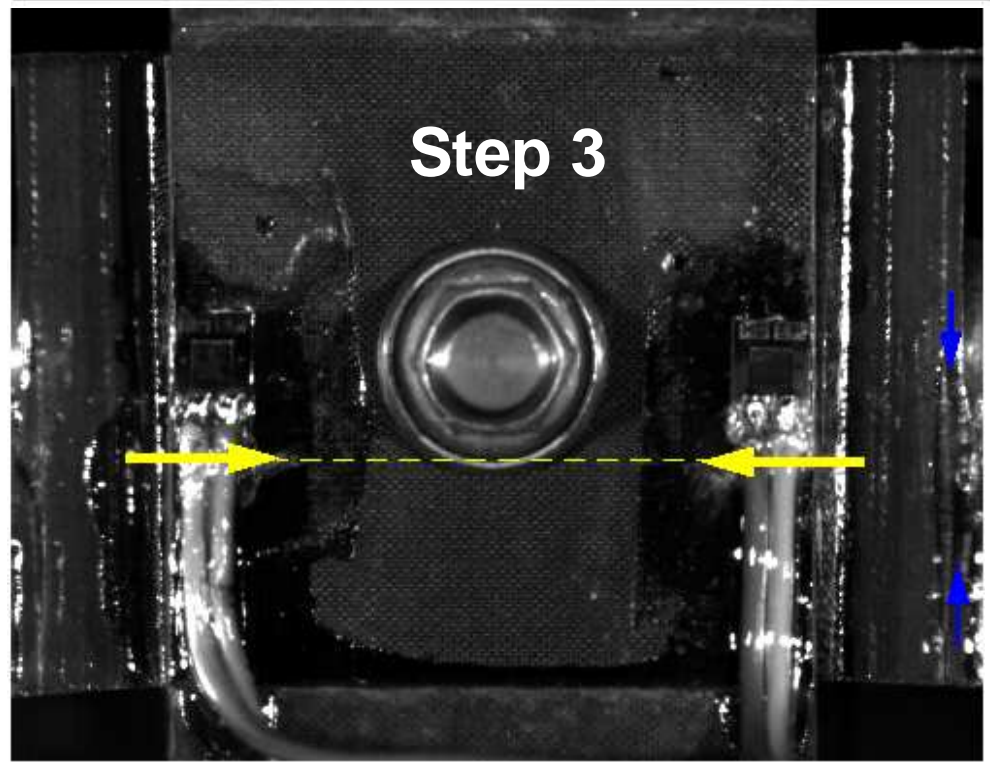

Local Bucking and failure of the delaminated plies

Figure $N^{\circ} 15$ : Failure scenario for [2/4/4/10] stack ing specimens. 